\title{
Norm values and psychometric properties for the German health regulatory focus scale - results of a representative survey
}

\author{
Bjarne Schmalbach $^{1 *}$ D, Markus Zenger ${ }^{2,3}$, Elmar Brähler ${ }^{1}$ and Katja Petrowski ${ }^{4}$
}

\begin{abstract}
Background: The health regulatory focus is an application of Higgins' regulatory focus theory to a health-specific context. It explains individual differences in health motivation, strategies, and behavior. Previous research found the Health Regulatory Focus Scale (HRFS) to be a reliable and valid measure for the construct. However, an evaluation of the HRFS in a representative sample has not been performed as of yet. Neither are there any normative values available.

Methods: We collected a representative sample from the German general population to perform a confirmatory factor analysis, an analysis of measurement invariance, and to calculate norm values.

Results: A two-factor model evinced good model fit with a good reliability for the two subscales. We found evidence for strict invariance across gender groups and partial strict invariance across age groups. In addition, we are presenting normative values for the general population.

Conclusions: The findings of the present study are in line with previous research in confirming the HRFS as a valid and reliable tool suitable for the assessment of the health regulatory focus. The reported normative values allow for comparisons of individuals with their respective sociodemographic group.
\end{abstract}

Keywords: Regulatory focus, Health, Short scale, Psychometric properties, Norm values

\section{Background}

The World Health Organization (WHO) defines health as "complete physical, mental, and social well-being and not merely the absence of disease or infirmity" $[1 ; \mathrm{p} .1]$. Hereby, the avoidance of risks as well as the effort toward general wellness is of importance. In order to ensure the efficacy of health interventions, the target population must be specified as accurately as possible [2] and the interventions modified to the specific needs [3] Therefore, individual differences concerning health behavior, needs, and strategies used to improve one's health need to be taken into account.

To allow for an efficient assessment of individual differences in health motivation and behavior, Gomez and colleagues [4] developed the Health Regulatory Focus Scale (HRFS) evaluating the health-specific regulatory

\footnotetext{
* Correspondence: bjarne.schmalbach@gmail.com

${ }^{1}$ Department of Psychosomatic Medicine and Psychotherapy, University Medical Center of the Johannes Gutenberg University Mainz, Untere

Zahlbacher Str. 8, 55131 Mainz, Germany

Full list of author information is available at the end of the article
}

focus. The questionnaire assesses health promotion as well as health prevention. It is based on the regulatory focus theory which deals with gain- and loss-orientation in a general context [5] and has been adapted from general constructs to fit into the health context [4]. Based on previous research [6, 7], health promotion items focus on seeking and seizing opportunities to improve one's health while health prevention items capture the attempts to avert dangers to one's health.

Correlations between health prevention focus and health promotion focus vary between $r=0.16$ and $r=0.57$ [4]. In terms of convergent and discriminant validity, health promotion focus shows moderate correlations with optimism, positive self-evaluations, and approach motivation [8-10]. In contrast, health prevention focus is associated with neuroticism, negative self-evaluations, motivational inhibition, and impaired mental health $[8,11]$. Finally, health promotion predicts health outcomes positively, while health prevention is associated negatively $[12,13]$.

(c) The Author(s). 2020 Open Access This article is distributed under the terms of the Creative Commons Attribution 4.0 International License (http://creativecommons.org/licenses/by/4.0/), which permits unrestricted use, distribution, and reproduction in any medium, provided you give appropriate credit to the original author(s) and the source, provide a link to the Creative Commons license, and indicate if changes were made. The Creative Commons Public Domain Dedication waiver (http://creativecommons.org/publicdomain/zero/1.0/) applies to the data made available in this article, unless otherwise stated. 
For the German HRFS, reliability and item characteristics were found to be satisfactory [8]. Based on confirmatory factor analysis (CFA), a two-factor solution fits best for the HRFS. However, measurement invariance for gender and age was unclear due to Heywood cases. Furthermore, the sample was collected online and made up mainly of young female participants. Thus, it cannot be considered representative of the general population. Euhus et al. [9] addressed these concerns to some extent, but did not analyze a representative sample either.

In order to use and interpret individual results of the HRFS, normative values of a representative sample of the general population must be available. Therefore, the purpose of the present study is twofold. First, the aim is to build upon Schmalbach and colleagues [8] and find additional evidence for the psychometric qualities of the HRFS. Second, we seek to establish norm values for the HRFS to allow for the evaluation of individuals based on representative data from the German population.

\section{Method}

\section{Participants}

The full study sample consisted of 2510 participants. Of those, 2469 responded to all HRFS items and 40 responded to at least one of the items so that we were able to use their data in the factor analysis (see analysis section for more details). For descriptive statistics, comparisons, and norm values, only participants with complete data were included. Figure 1 illustrates the sample flow. A detailed sample description is reported in the Results section.

\section{Material}

Gomez and colleagues [4] developed the HRFS to measure the promotion and prevention focus in health-specific contexts. Schmalbach and colleagues [8] translated the scale using a back-translation process and adapted it based on psychometric considerations. The German version has five items measuring the health promotion focus and two items for the health prevention focus. Response options are presented on a 7-point-scale ranging from (1) "strongly disagree" to (7) "strongly agree". Taking the average of the items in question yields the respective scale scores for health promotion and health prevention. Apart from the HRFS, the participants gave their sociodemographic information.

In addition, we applied the Patient Health Questionnaire-4 (PHQ-4 [14]) to further test convergent validity. It is a screening instrument for anxiety and depression. As such it is one of the most widely-applied tools for the assessment of mental health. Respondents rate the frequency of symptoms of depression and anxiety they have experienced using two items each on a four-point scale ranging from "Not at all" to "Nearly every day". Two subscale scores and a total score are calculated by adding up the item scores, $\omega_{\text {Anxiety }}=.798$ [.780; $.817], \omega_{\text {Depression }}=.807[.801 ; .824], \omega_{\text {Total }}=.879[.865 ; .892]$.

\section{Procedure}

A representative sample of the general population of Germany was collected in 2016 by a demography consulting company (USUMA, Berlin). Per random-route procedure, households in all regions of Germany (based on electoral districts) were selected. Among the 4838 selected addresses, 2324 households (48\%) could not be interviewed (e.g., illness, on holiday, refusal, unavailability) and 4 interviews $(0.1 \%)$ were not analyzable (see Fig. 1). Within each household, the interviewee was selected based on the Kish selection grid. A trained professional then conducted the interviews with the consenting participants (oral consent in accordance with German law). The resulting sample was representative for the German community regarding age, gender, and education, as evidenced by comparisons with the Federal Statistical Office [15].

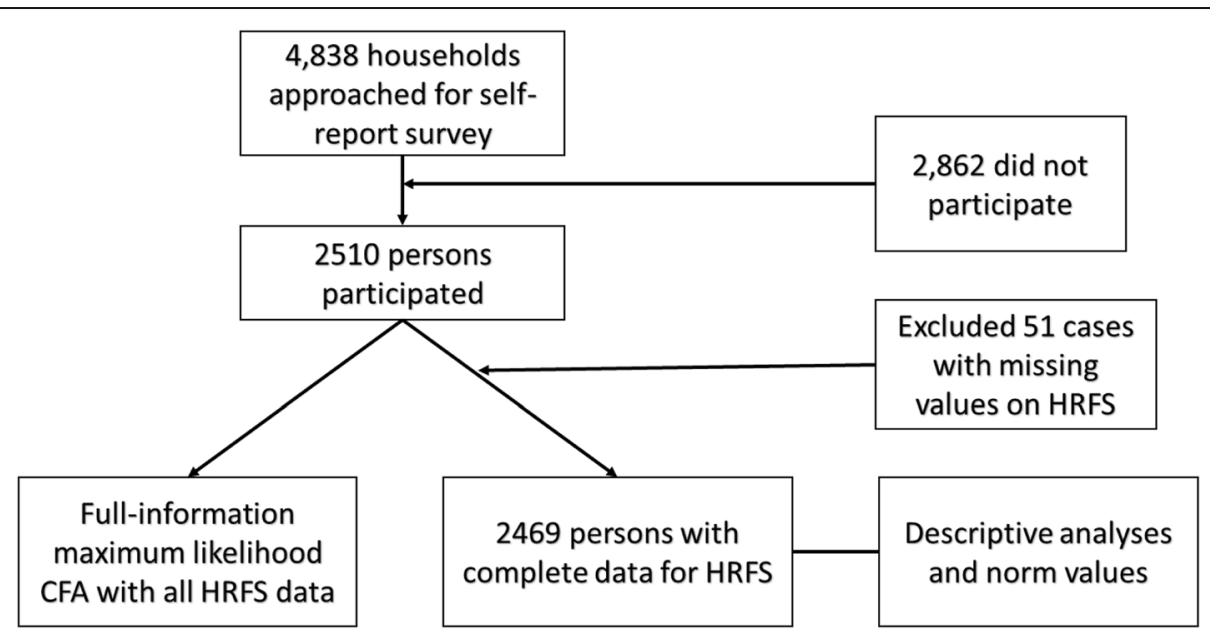

Fig. 1 Sample flow chart 


\section{Analysis}

We conducted the statistical analysis using $\mathrm{R}$ and the packages lavaan and semTools $[16,17]$. To enable the inclusion of participants with partially missing data and in order to address the slightly skewed and kurtotic distribution of some items, we used the robust fullinformation maximum likelihood estimation method with Yuan-Bentler's scaled $X^{2}[18-21]$. To evaluate goodness-of-fit, we utilized popular fit indices with commonly recommended cut-off criteria for good fit [2224]: The $x^{2}$-test which should ideally not be significant; $x^{2}$ divided by degrees of freedom (CMIN/DF), which should be smaller than 3; the Comparative Fit Index (CFI), and the Tucker-Lewis Index (TLI), which should be larger than .95, the Root Mean Square Error of Approximation (RMSEA) and its 90\% confidence interval, and the Standardized Root Means Square Residual (SRMR), which should be smaller than .08 .
We tested measurement invariance across age and gender using the procedure recommended by previous research $[25,26]$ : We compared increasingly constrained models in a stepwise fashion to establish increasingly strict levels of invariance. Firstly, we tested metric (or weak) invariance by comparing the unconstrained model with a model that constrains factor loadings to be equal across groups. Secondly, we tested scalar (or strong) invariance by comparing the metric model to one that additionally constrains item intercepts to be equal. Finally, we tested strict invariance by comparing the scalar model to a model that also constrains residuals to be equal across tested groups. As recommended by Milfont and Fischer [26], we evaluated model comparisons using the $X^{2}$-test as well as differences in CFI and gamma hat (GH [27];). $X^{2}$ should ideally not be significant, and $\Delta \mathrm{CFI}$ and $\Delta \mathrm{GH}$ should not be larger than .01 between models. As per recommendations by Trizano-Hermosilla and

Table 1 Sociodemographic characteristics of the sample along with comparisons in HRFS

\begin{tabular}{|c|c|c|c|c|}
\hline & $\mathrm{N}$ & $\%$ & HRFS Promotion & HRFS Prevention \\
\hline Gender & & & $F(1,2464)=49.28, p<.001, \eta_{p}^{2}=.020$ & $F(1,2464)=19.94, p<.001, \eta_{p}^{2}=.008$ \\
\hline Female & 1339 & 53.3 & $4.41^{\mathrm{a}}(1.40)$ & $3.42^{\mathrm{a}}(1.61)$ \\
\hline Male & 1171 & 46.7 & $4.01^{\mathrm{b}}(1.49)$ & $3.13^{\mathrm{b}}(1.65)$ \\
\hline Age groups (years) & & & $F(2,2463)=7.32, p=.001, \eta_{p}^{2}=.006$ & $F(2,2463)=24.97, p<.001, \eta_{p}^{2}=.020$ \\
\hline$\leq 39$ & 873 & 34.8 & $4.07^{\mathrm{a}}(1.47)$ & $2.97^{\mathrm{a}}(1.62)$ \\
\hline $40-59$ & 893 & 35.6 & $4.30^{\mathrm{b}}(1.45)$ & $3.39^{\mathrm{b}}(1.61)$ \\
\hline$\geq 60$ & 744 & 29.6 & $4.32^{\mathrm{b}}(1.43)$ & $3.52^{\mathrm{b}}(1.62)$ \\
\hline Education & & & $F(3,2453)=7.80, p<.001, \eta_{p}^{2}=.009$ & $F(3,2453)=18.48, p<.001, \eta_{p}^{2}=.022$ \\
\hline$\geq 9$ years & 809 & 32.2 & $4.21^{\mathrm{a}}(1.41)$ & $3.55^{\mathrm{a}}(1.64)$ \\
\hline 10 years & 1071 & 42.7 & $4.30^{\mathrm{a}}(1.50)$ & $3.26^{\mathrm{b}}(1.61)$ \\
\hline$\leq 11$ years & 543 & 21.6 & $4.22^{\mathrm{a}}(1.36)$ & $3.06^{\mathrm{C}}(1.58)$ \\
\hline Pupil/Student & 78 & 3.1 & $3.51^{\mathrm{b}}(1.73)$ & $2.38^{d}(1.75)$ \\
\hline Missing & 9 & 0.4 & & \\
\hline Family & & & $F(5,2451)=3.78, p=.002, \eta_{p}^{2}=.008$ & $F(5,2451)=4.71, p<.001, \eta_{p}^{2}=.010$ \\
\hline Married & 1093 & 43.5 & $4.25^{\mathrm{a}}(1.42)$ & $3.27^{\mathrm{a}}(1.63)$ \\
\hline Separated & 53 & 2.1 & $4.36^{\mathrm{a}}(1.57)$ & $3.55^{\mathrm{a}}(1.58)$ \\
\hline Single & 614 & 24.5 & $4.02^{\mathrm{b}}(1.48)$ & $3.11^{\mathrm{a}}(1.67)$ \\
\hline Divorced & 347 & 13.8 & $4.34^{\mathrm{a}}(1.49)$ & $3.32^{\mathrm{a}}(1.53)$ \\
\hline Widowed & 221 & 8.8 & $4.38^{\mathrm{a}}(1.45)$ & $3.70^{\mathrm{b}}(1.68)$ \\
\hline Committed Relationship & 173 & 6.9 & $4.37^{\mathrm{a}}(1.38)$ & $3.30^{\mathrm{a}}(1.61)$ \\
\hline Missing & 9 & 0.4 & & \\
\hline Employment & & & $F(3,2443)=6.95, p<.001, \eta_{p}^{2}=.008$ & $F(3,2443)=16.78, p<.001, \eta_{p}^{2}=.020$ \\
\hline Working & 1415 & 56.4 & $4.23^{\mathrm{a}}(1.45)$ & $3.18^{\mathrm{a}}(1.60)$ \\
\hline Retired & 638 & 25.4 & $4.36^{\mathrm{a}}(1.43)$ & $3.60^{\mathrm{b}}(1.64)$ \\
\hline School/Apprenticeship & 203 & 8.1 & $3.83^{\mathrm{b}}(1.53)$ & $2.77^{c}(1.67)$ \\
\hline Not working & 235 & 9.4 & $4.21^{\mathrm{a}}(1.44)$ & $3.45^{\mathrm{b}}(1.61)$ \\
\hline Missing & 19 & 0.8 & & \\
\hline
\end{tabular}

Means (Standard Deviations) of the HRFS subscales for each sociodemographic group, along with ANOVAs. Differing superscripts denote significant differences between sociodemographic groups 
Table 2 Item and scale characteristics

\begin{tabular}{lllllll}
\hline & $M$ & $S D$ & $\gamma_{1}$ & $\gamma_{2}$ & $r_{\text {it }}$ & $\lambda$ \\
\hline HRFS Item 1 & 4.44 & 1.75 & -.30 & -.80 & .71 & .74 \\
HRFS Item 2 & 4.32 & 1.66 & -.24 & -.68 & .81 & .83 \\
HRFS Item 3 & 3.94 & 1.67 & .02 & -.72 & .77 & .82 \\
HRFS Item 4 & 4.24 & 1.64 & -.17 & -.69 & .82 & .87 \\
HRFS Item 5 & 4.20 & 1.68 & -.12 & -.78 & .83 & .88 \\
HRFS Promotion scale & 4.23 & 1.45 & -.19 & -.48 & & \\
HRFS Item 6 & 3.44 & 1.84 & .27 & -1.03 & .68 & .85 \\
HRFS Item 8 & 3.13 & 1.72 & .42 & -.78 & .68 & .81 \\
HRFS Prevention scale & 3.29 & 1.63 & .30 & -.80 & & \\
\hline
\end{tabular}

$\gamma_{1}$ skewness, $\gamma_{2}$ excessive kurtosis, $r_{i t}$ corrected item-total-correlation, $\lambda$ standardized factor loadings
Alvarado [28], we report McDonald's $\omega$ [29] as a measure of internal consistency.

\section{Results}

We report a detailed description of the sample in Table 1. Participants were on average 48.36 years old $(S D=18.22)$. The mean monthly net household income was 2592.86 euros $(S D=1485.10$ euros). It correlated very weakly with health promotion, $r(2,362)=.026$, $p=.206$, and health prevention focus, $r(2,362)=-.078$, $p<.001$. The sample can be considered as representative of the German population.

The Shapiro-Wilk test for normal distribution was highly significant, $p<.001$, for all items and both scales. Considering our sample size, however, this is not surprising. Instead, Kim [30] recommends the analysis of skewness and kurtosis of the distributions. Absolute values for skewness should be smaller than 2 and excessive kurtosis

Table 3 Analysis of measurement invariance

\begin{tabular}{|c|c|c|c|c|c|c|c|}
\hline Model & $x^{2}(d f)$ & $\Delta x^{2}$ & $p$ & CFI & $\Delta C F I$ & GH & $\Delta G H$ \\
\hline \multicolumn{8}{|c|}{ Gender multi-group analysis (female / male) } \\
\hline Configural invariance & $248.92(26)$ & & & .967 & & .951 & \\
\hline Metric invariance & $265.85(31)$ & 16.93 & .342 & .965 & .002 & .949 & .002 \\
\hline Scalar invariance & $278.93(36)$ & 13.08 & $<.001$ & .964 & .001 & .947 & .002 \\
\hline Strict invariance & $269.00(43)$ & 9.93 & .248 & .967 & .003 & .951 & .004 \\
\hline \multicolumn{8}{|c|}{ Age multi-group analysis $(\leq 39,40-59, \geq 60)$} \\
\hline Configural invariance & $250.44(39)$ & & & .970 & & .932 & \\
\hline Metric invariance & $274.31(49)$ & 23.87 & .008 & .968 & .002 & .927 & .005 \\
\hline Scalar invariance & $409.34(59)$ & 135.03 & $<.001$ & .950 & .018 & .891 & .036 \\
\hline Partial scalar invariance ${ }^{a}$ & $298.23(53)$ & 23.92 & $<.001$ & .965 & .003 & .922 & .005 \\
\hline Partial strict invariance ${ }^{a}$ & $294.17(67)$ & 4.06 & .852 & .967 & .002 & .927 & .005 \\
\hline \multicolumn{8}{|c|}{ Education multi-group analysis ( $\geq 9$ years, 10 years, $\leq 11$ years) } \\
\hline Configural invariance & $249.921(39)$ & & & .973 & & .976 & \\
\hline Metric invariance & $272.582(49)$ & 22.661 & .012 & .973 & .000 & .974 & .002 \\
\hline Scalar invariance & $335.692(59)$ & 63.110 & $<.001$ & .967 & .006 & .968 & .006 \\
\hline Strict invariance & $332.419(73)$ & 3.273 & .998 & .967 & .000 & .970 & .002 \\
\hline \multicolumn{8}{|c|}{ Family status multi-group analysis (married, single, divorced, widowed) } \\
\hline Configural invariance & $241.489(52)$ & & & .973 & & .976 & \\
\hline Metric invariance & $288.811(67)$ & 47.322 & $<.001$ & .972 & .001 & .973 & .003 \\
\hline Scalar invariance & $378.669(82)$ & 89.858 & $<.001$ & .965 & .007 & .964 & .009 \\
\hline Strict invariance & $415.905(103)$ & 37.236 & .016 & .960 & .005 & .962 & .002 \\
\hline \multicolumn{8}{|c|}{ Employment status multi-group analysis (working, retired, school/apprenticeship, not working) } \\
\hline Configural invariance & $273.037(52)$ & & & .974 & & .975 & \\
\hline Metric invariance & $306.536(67)$ & 33.499 & .004 & .974 & .000 & .973 & .002 \\
\hline Scalar invariance & $457.330(82)$ & 150.794 & $<.001$ & .960 & .014 & .959 & .014 \\
\hline Partial scalar invariance ${ }^{\mathrm{b}}$ & $402.601(79)$ & 96.065 & $<.001$ & .965 & .009 & .964 & .009 \\
\hline Partial strict invariance ${ }^{\mathrm{b}}$ & $422.636(100)$ & 20.035 & .331 & .963 & .002 & .964 & .000 \\
\hline
\end{tabular}

antercepts of Items 1, 2, and 4 were freed to vary between groups in these models

${ }^{\mathrm{b}}$ The intercept of Item 2 was freed to vary between groups in these models 
smaller than 4, which was the case with our items and scales. Reliability for the promotion scale is $\omega=.916$ [910, 923] while the prevention scale had a reliability of $\omega=.813$ [.805; .821]. Further statistics are reported in Table 2.

Overall, the model fits reasonably well, $\chi^{2}(13)=229.53$, $p<.001, \chi^{2} / d f=17.66, \quad C F I=.968, \quad R M S E A=.081 \quad[.074$; .089 ], $T L I=.949, S R M R=.022$, confirming the findings by Schmalbach and colleagues [8]. Specifically, the $x^{2}$-test and $x^{2}$ divided by degrees of freedom indicate bad fit, which is not surprising given $\chi^{2}$ s sensitivity to sample size [31]. The fit indices, on the other hand, reveal an acceptable model fit. CFI and SRMR present evidence for good fit, whereas RMSEA and TLI are barely acceptable.

We found clear evidence for strict invariance across gender groups, as evidenced by small differences in CFI and GH (see Table 3). The $x^{2}$-test was significant in one of the three comparisons. For age groups, we found evidence for metric invariance. By freeing the intercepts of items 1,2 , and 4 to vary between groups, we were able to show partial strict invariance. In addition, we tested for invariance across education, family, and employment status, utilizing these subgroups (from Table 1) that had at least 200 observations. For education and family, the evidence suggest strict invariance, whereas for employment status there were some differences with regard to item intercepts. However, partial strict invariance could be established for this grouping variable. Overall, the HRFS appears to be highly invariant across sociodemographic variables - with some minor limitations with regard to age and employment.

Confirming previous findings [8], we found moderate positive associations between health prevention focus and impaired mental health, $r(2467)=.264, p<.001$. Expanding on this, anxiety and depression exhibited comparable correlations, $r(2467)=.246, r(2467)=.250$, both $p<.001$. In contrast - again in line with [8] -, there were near-zero correlations for health promotion focus, $r_{\text {Anxiety }}(2467)=.059, \quad p=.003, \quad r_{\text {Depression }}(2467)=.018$, $p=.371, r_{\mathrm{PHQ}-4}(2467)=.041, p=.042$.

Norm values are reported in Table 4. Since there are no meaningful differences between the middle-aged (40-59 years) and the older ( $\geq 60$ years) group, we merged these groups. We report means and standard deviations of the HRFS as well as quantiles to allow for the classification of individual scores.

\section{Discussion}

The goal of the present study was to replicate and extend the findings by Schmalbach and colleagues [8] by testing the proposed HRFS model in a large sample representative of the German general population. This aim was accomplished. We found acceptable fit for the model proposed by Schmalbach and colleagues. Interestingly, the association between mental
Table 4 Norm values with quantiles

\begin{tabular}{|c|c|c|c|c|}
\hline \multirow{2}{*}{$\begin{array}{l}\text { Gender } \\
\text { Age (years) }\end{array}$} & \multicolumn{2}{|l|}{ Female } & \multicolumn{2}{|l|}{ Male } \\
\hline & $\leq 39(n=449)$ & $\geq 40(n=867)$ & $\leq 39(n=411)$ & $\geq 40(n=739)$ \\
\hline \multicolumn{5}{|c|}{ HRFS promotion } \\
\hline M & 4.28 & 4.50 & 3.86 & 4.10 \\
\hline$S D$ & 1.44 & 1.37 & 1.48 & 1.49 \\
\hline $1 \%$ & 1.00 & 1.20 & 1.00 & 1.00 \\
\hline $5 \%$ & 1.40 & 2.00 & 1.00 & 1.40 \\
\hline $10 \%$ & 2.20 & 2.60 & 1.80 & 2.00 \\
\hline $25 \%$ & 3.40 & 3.60 & 2.80 & 3.00 \\
\hline $50 \%$ & 4.40 & 4.60 & 4.00 & 4.00 \\
\hline $75 \%$ & 5.20 & 5.40 & 4.80 & 5.20 \\
\hline $90 \%$ & 6.20 & 6.20 & 5.80 & 6.20 \\
\hline $95 \%$ & 6.40 & 7.00 & 6.40 & 6.60 \\
\hline $99 \%$ & 7.00 & 7.00 & 7.00 & 7.00 \\
\hline \multicolumn{5}{|c|}{ HRFS prevention } \\
\hline M & 3.16 & 3.56 & 2.78 & 3.33 \\
\hline$S D$ & 1.62 & 1.60 & 1.60 & 1.64 \\
\hline $1 \%$ & 1.00 & 1.00 & 1.00 & 1.00 \\
\hline $5 \%$ & 1.00 & 1.00 & 1.00 & 1.00 \\
\hline $10 \%$ & 1.00 & 1.50 & 1.00 & 1.00 \\
\hline $25 \%$ & 2.00 & 2.50 & 1.00 & 2.00 \\
\hline $50 \%$ & 3.00 & 3.50 & 2.50 & 3.50 \\
\hline $75 \%$ & 4.50 & 4.50 & 4.00 & 4.50 \\
\hline $90 \%$ & 5.50 & 6.00 & 5.00 & 5.50 \\
\hline $95 \%$ & 6.00 & 6.50 & 5.50 & 6.00 \\
\hline $99 \%$ & 7.00 & 7.00 & 7.00 & 7.00 \\
\hline
\end{tabular}

health and the health prevention focus was significantly smaller in the present study compared to the study by Schmalbach and colleagues [8]. This might be an effect of the skewed sample they used - over-representing young individuals. It is an indication that the correlation between the health regulatory focus and related constructs may differ across age.

The novel contribution of the present study lies in the analysis of measurement invariance, which previously had been lacking. Namely, we found the HRFS to be strictly invariant across gender, education, and family status, as well as partially strictly invariant across age groups and employment status. Additionally, we report norm values for age and gender groups (see Table 4). The findings of the present study allow researchers to apply the HRFS in a wider variety of research designs. Measurement invariance is an important prerequisite for comparisons between groups. Moreover, normative values will allow for the assessment of an individual's health regulatory focus, which will be useful for designing health-focused interventions. 
The HRFS is, as of now, the only reliable and valid tool available to German researchers for the assessment of the health regulatory focus. Ferrer, Lipkus, Cerully, McBride, Shepperd, and Klein [32] developed and tested an alternative version of an HRFS. However, they could not confirm their model in CFA.

\section{Limitations}

Applications of the HRFS to address innovative research questions are still outstanding. As a reviewer pointed out, future research should look into how chronic diseases, migration status or cultural background impact health regulatory focus. These are important and innovative questions but were beyond the scope of the present article. Some research has already tackled similar issues [33, 34], but the health-specific HRFS will allow for large-scale surveys to answer these questions on a population level.

\section{Conclusion}

The German HRFS was evaluated as a reliable and valid measure of the health regulatory focus. We have extended the findings by Schmalbach and colleagues [8] by adding an unambiguous analysis of measurement invariance and normative values. Thus, we can reiterate the original recommendation for the HRFS as a tool for psychological research into health behavior and motivation.

\footnotetext{
Abbreviations

CFA: Confirmatory Factor Analysis; CFI: Comparative Fit Index; CMIN/ DF: Minimum discrepancy divided by degrees of freedom; GH: Gamma hat; HRFS: Health Regulatory Focus Scale; PHQ: Patient Health Questionnaire; RMSEA: Root Mean Square Error of Approximation; SRMR: Standardized Root Mean Square Residual; TLI: Tucker-Lewis Index; USUMA: Unabhängiger Service für Umfragen, Methoden und Analysen [Independent Service for Surveys, Methods, and Analyses]
}

\section{Authors' contributions}

All the authors participated in writing the paper and made substantial contributions while working on the article. BS and MZ did the statistics. KP and EB designed the study and supervised the data collection. All the authors agreed to be accountable for the content of the study. All the authors read and approved the final manuscript.

\section{Funding}

The authors received no funding for the reported research.

\section{Availability of data and materials}

The dataset used and analyzed in the current study is available from the corresponding author on reasonable request.

\section{Ethics approval and consent to participate}

The present study was conducted in accordance with the Declaration of Helsinki. The study was approved by the ethics committee of the University of Leipzig (ref. 297/16-ek). Participants gave their written and verbal informed consent before they were allowed to participate in the study. Participants under the age of 18 were not recruited.

\section{Consent for publication}

Not applicable.

\section{Competing interests}

The authors declare that they have no competing interests.

\section{Author details}

'Department of Psychosomatic Medicine and Psychotherapy, University Medical Center of the Johannes Gutenberg University Mainz, Untere Zahlbacher Str. 8, 55131 Mainz, Germany. ${ }^{2}$ Faculty of Applied Human Studies, University of Applied Sciences Magdeburg-Stendal, Osterburger Str. 25, 39576 Stendal, Germany. ${ }^{3}$ Integrated Research and Treatment Center AdiposityDiseases - Behavioral Medicine, Psychosomatic Medicine and Psychotherapy, University of Leipzig Medical Center, Philipp-Rosenthal-Straße 27, 04103 Leipzig, Germany. ${ }^{4}$ Medical Psychology \& Medical Sociology, University Medical Center of the Johannes Gutenberg University Mainz, Saarstraße 21, 55099 Mainz, Germany.

Received: 31 August 2018 Accepted: 17 February 2020

Published online: 02 March 2020

\section{References}

1. World Health Organization. Constitution of the World Health Organization. New York: World Health Organization; 2006. Retrieved from http://www. who.int/governance/eb/who_constitution_en.pdf.

2. Thacker SB, Stroup DF, Carande-Kulis V, Marks JS, Roy K, Gerberding JL. Measuring the public's health. Public Health Rep. 2006. https://doi.org/10. 1177/003335490612100107.

3. Peeling RW, Smith PG, Bossuyt PMM. A guide for diagnostic evaluations. Nat Rev Microbiol. 2010. https://doi.org/10.1038/nrmicro1568.

4. Gomez P, Borges A, Pechmann C. Avoiding poor health or approaching good health: does it matter? The conceptualization, measurement, and consequences of health regulatory focus. J Consum Psychol. 2013. https:// doi.org/10.1016/j.jcps.2013.02.001

5. Higgins ET. Beyond pleasure and pain. Am Psychol. 1997. https://doi.org/10. 1037/0003-066X.52.12.1280.

6. Avnet T, Higgins ET. How regulatory fit affects value in consumer choices and opinions. J Mark Res. 2006. https://doi.org/10.1509/jmkr.43.1.1.

7. Pham MT, Higgins ET. Promotion and prevention in consumer decision making state of the art and theoretical propositions. In: Ratneshwar SM, Mick DG, editors. Inside consumption: frontiers of research on consumer motives, goals, and desires. London: Routledge; 2005. p. 8-43.

8. Schmalbach B, Spina R, Steffens-Guerra I, Franke GH, Kliem S, Michaelides MP, Hinz A, Zenger M. Psychometric properties of the German version of the health regulatory focus scale. Front Psychol. 2017;8:2005.

9. Euhus A, Schmalbach B, Morfeld M, Berth H, Brähler E, Stobel-Richter $Y$, Zenger M. Psychometric evaluation of the German version of the health regulatory focus scale [Psychometrische Uberprufung der deutschen version der health regulatory focus scale]. Z Psychosom Med Psychother. 2018;64: 394-411.

10. Grant H, Higgins ET. Optimism, promotion pride, and prevention pride as predictors of quality of life. Personal Soc Psychol Bull. 2003. https://doi.org/ 10.1177/0146167203256919.

11. Otonari J, Nagano J, Morita M, Budhathoki S, Tashiro N, Toyomura K, et al. Neuroticism and extraversion personality traits, health behaviours, and subjective well-being: the Fukuoka study (Japan). Q Life Res. 2012. https:// doi.org/10.1007/s11136-011-0098-y.

12. Elliot AJ, Sheldon KM. Avoidance personal goals and the personality-illness relationship. J Pers Soc Psychol. 1998. https://doi.org/10.1037/0022-3514.75.5.1282.

13. Jung M, Ramanadhan S, Viswanath K. Effect of information seeking and avoidance behavior on self-rated health status among cancer survivors. Patient Educ Couns. 2013. https://doi.org/10.1016/j.pec.2013.02.008.

14. Löwe B, Wahl I, Rose M, Spitzer C, Glaesmer H, Wingenfeld K, et al. A 4-item measure of depression and anxiety: validation and standardization of the Patient Health Questionnaire-4 (PHQ-4) in the general population. J Affect Disord. 2010;122:86-95.

15. Federal Statistical Office of Germany. Bevölkerung [population]; 2016. Retrieved from https://www.destatis.de/DE/ZahlenFakten/GesellschaftStaat/ Bevoelkerung/Bevoelkerung.html.

16. Rosseel Y. Lavaan: an R package for structural equation modeling. J Stat Softw. 2012;48:1-36 URL http://www.jstatsoft.org/v48/i02/.

17. semTools Contributors. semTools: useful tools for structural equation modeling. 2016. R package version 0.4-14. Retrieved from https://CRAN.Rproject.org/package=semTools.

18. Enders CK. A primer on maximum likelihood algorithms available for use with missing data. Struct Equ Model. 2001;8:128-41. 
19. Finney SJ, DiStefano C. Non-normal and categorical data in structural equation modeling. In: Hancock GR, Mueller RO, editors. Structural equation modeling: a second course. 2nd ed. Charlotte: Information Age Publishing; 2013. p. 439-793.

20. Schafer JL, Graham JW. Missing data: our view of the state of the art. Psychol Methods. 2002;7:147-77.

21. Yuan KH, Bentler PM. Three likelihood-based methods for mean and covariance structure analysis with nonnormal missing data. Sociol Methodol. 2000;30:165-200.

22. Hu LT, Bentler PM. Fit indices in covariance structure modeling: sensitivity to underparameterized model misspecification. Psychol Methods. 1998;3:424-53.

23. Hu LT, Bentler PM. Cutoff criteria for fit indexes in covariance structure analysis: conventional criteria versus new alternatives. Struct Equ Model Multidiscip J. 1999;6:1-55.

24. Schermelleh-Engel K, Moosbrugger $\mathrm{H}$, Müller $\mathrm{H}$. Evaluating the fit of structural equation models: tests of significance and descriptive goodnessof-fit measures. Methods Psychol Res Online. 2003;8:23-74.

25. Cheung GW, Rensvold RB. Evaluating goodness-of-fit indexes for testing measurement invariance. Struct Equ Model. 2002;9:233-55.

26. Milfont TL, Fischer R. Testing measurement invariance across groups: applications in crosscultural research. Int J Psychol Res. 2010;3:111-21.

27. Steiger JH. EZPATH: a supplementary module for SYSTAT and SYGRAPH. Evanston: Systat; 1989

28. Trizano-Hermosilla I, Alvarado JM. Best alternatives to Cronbach's alpha reliability in realistic conditions: congeneric and asymmetrical measurements. Front Psychol. 2016. https://doi.org/10.3389/fpsyg.2016.00769.

29. McDonald R. Test theory: a unified treatment. Mahwah: Lawrence Erlbaum Associates; 1999.

30. Kim HY. Statistical notes for clinical researchers: assessing normal distribution (2) using skewness and kurtosis. Restor Dent Endod. 2013;38:52-4.

31. Bentler PM, Bonett DG. Significance tests and goodness of fit in the analysis of covariance structures. Psychol Bull. 1980;88:588-606.

32. Ferrer RA, Lipkus IM, Cerully JL, McBride CM, Shepperd JA, Klein WM. Developing a scale to assess health regulatory focus. Soc Sci Med. 2017;195: 50-60.

33. Ludolph R, Schulz PJ. Does regulatory fit lead to more effective health communication? A systematic review. Soc Sci Med. 2015;128:142-50.

34. Uskul AK, Sherman DK, Fitzgibbon J. The cultural congruency effect: culture, regulatory focus, and the effectiveness of gain-vs. loss-framed health messages. J Exp Soc Psychol. 2009;45:535-41.

\section{Publisher's Note}

Springer Nature remains neutral with regard to jurisdictional claims in published maps and institutional affiliations.

Ready to submit your research? Choose BMC and benefit from:

- fast, convenient online submission

- thorough peer review by experienced researchers in your field

- rapid publication on acceptance

- support for research data, including large and complex data types

- gold Open Access which fosters wider collaboration and increased citations

- maximum visibility for your research: over $100 \mathrm{M}$ website views per year

At $\mathrm{BMC}$, research is always in progress.

Learn more biomedcentral.com/submissions 